Brassey collection. Some of the specimens appear to belong to a dealer, Mr. Bryce-Wright, and to these and others he has assigned names as though he were a serious zoologist. This travesty of science should not have been permitted. The names attached to the specimens are either incorrect applications of existing names or are gratuitous inventions (as for instance that of Brasseya radians), which can only mislead persons not specially acquainted with the history of corals.

Amongst the gigantic lobsters, clams, and stuffed fish there are some few s̀mall collections of scientific merit in the British exhibit. Dr. Francis Day shows a series of British fishes (alcohol specimens), Prof. McIntosh of St. Andrew's some coloured drawings of marine animals admirably executed by his sister, and a series of specimens of the salmon at various stages of development. Dr. Traquair of Edinburgh shows some exquisite drawings of fossil fishes, and H.R.H. the Duke of Edinburgh a collection of shells, scientifically named and arranged.

The parasites of fishes are not well represented in any part of the Exhibition. Dr. Spencer Cobbold shows a small collection of internal and external parasites, and a still smaller series (having, however, some special interest) is to be seen in the Russian court, where also the naturalist should not fail to study Dr. Grimm's important collection illustrating the fauna of the Caspian Sea. The most remarkable exhibit in the way of parasites is that of Dr. Antonio Valli of Trieste, who shows (in the Austrian Court) a collection of eighty-five specimens of Copepod Crustacea parasitic on the fishes of the Adriatic, accompanied by drawings and descriptions.

Curiously enough there is next to nothing in the Exhibition illustrating the diseases of fish. Some stuffed salmon with cotton-wool attached in patches to the head and fins do duty for the "Saprolegnia disease," and a not too accurate drawing of the Saprolegnia itself is exhibited in a part of the building which is about a quarter of a mile distant from the stuffed specimens. In a third locality is a cast of a salmon with cotton-wool also gummed on to represent "the disease," and near it an insufficiently stuffed skin of an old Kelt, which is offered as an example of the effects of "the arrow-beaded parasite."

In the space occupied by Chili, China, and the Straits Settlements some specimens of fishes, and of shell-fish, corals, \&c., are shown, which are not however scientifically named.

Finally, we would direct the reader's attention to two peculiarly interesting branches of fishery which are represented, though very poorly, in the present Exhibition. These are the sponge fishery and the coral fishery: the pearl fishery appears not to be represented at all. Collections of economic importance, showing the mode of diving for sponges in use in the Levant, and samples of Turkey sponges are shown in the Greek Court by Messrs. Marks and Son. By mistake (as seems probable) a specimen of Hyalonema, from another locality, has been placed in the case containing this fine collection of officinal sponges. From the Bahamas samples of commercial sponges are sent, and also (of very, similar quality) from Florida (in the American Court). The propagation of sponges by cutting is illustrated by two specimens in the American collec- tion, but no attempt is anywhere made to show the officinal sponge in its natural state, or to illustrate its lifehistory and distribution.

Similarly as commercial products we have the precious coral exhibited in the Italian Court by Signor Criscuolo. This exhibitor, however, also shows the method of dredging employed in the Gulf of Naples for obtaining the coral, and displays a number of the wooden crossbars with stone weights attached, and hempen tangles depending, which constitute the instrument used in this fishery. Specimens of other corals and shell-fish found in association with the red coral are also exhibited.

In no exhibit is there any attempt to illustrate the natural history of the precious coral, although its interest is no less than its value.

A strange illustration of the chance uses of sucb an exhibition as the present may be found in the Japanese department. Nothing could be worse or more unworthy than the Japanese exhibit. It consists of some sardines, a large crab (Macrocheira), three pieces of red coral, and some silks and lacquer work. The three pieces of coral are the first commercial examples of a new species of precious coral which will henceforward form an important article of trade for Japan. They have been purchased by Signor Criscuolo at a high price, and are said to be of the very finest quality. The new Japanese coral fisheries are destined to make the fortunes of those who first set them going, and will very possibly seriously injure, if they do not ruin the Neapolitan fishermen. Similar precious coral may in all probability be discovered by dredging operations on the shores of one or more of the numerous British colonies.

On a future occasion we shall publish some notes by Prof. Giglioli of Florence, on the whales, seals, birds, and fishes now to be seen at the Exhibition.

\section{PRECAUTIONS AGAINST CHOLERA}

HARLY in the month the Local Government Board L issued an Order to Port Sanitary Authorities conferring upon them special powers with a view of preventing the importation of cholera into this country. But cholera is a disease having many degrees of severity, and although "choleraic-diarrhœa" is to be regarded by the Port Authorities as synonymous with the fully developed affection, yet it is at times so mild that it may at any moment escape detection, and those suffering from it may make their way into our towns and villages. To meet such emergencies, and by way of aiding inland authorities and private individuals to rid their districts and their homes of the conditions favourable to the propagation of the cholera infection, a Memorandum on the Precautions against the Infection of Cholera has just been issued by Dr. Buchanan, F.R.S., the chief medical officer of the Local Government Board. The document, whilst expressing no opinion as to the channels of infection and the means of favouring the spread of the disease in other climates, declares with confidence that in England cholera is not infectious in the same degree and manner as are small-pox and scarlet fever, but that the matters which the patient discharges from his stomach and bowels contain the poison, and that their peculiar infectiveness is favoured by special local conditions which give the disease 
facilities for spreading by "indirect infection." To get rid of these conditions should be our special aim at sucb a moment.

We have already pointed out how the poisonous discharges infect all receptacles into which they may be received and which tend to retain them, such as cesspools, sewers, and drains; how, when these receptacles are leaky, the soil around them becomes infected, leading to the pollution of air and of the water-bearing strata ; and to a less extent it must be remembered that clothing and linen which have become soiled by these discharges are in a similar way liable to retain the infection. But of all these sources of infection none are so dangerous as those which are liable to infect our public water-services; indeed single attar.ks of cholera in its slightest form may, if the discharges can by means of streams or otherwise reach our water-sources or reservoirs, "exert a terribly infective power on considerable masses of population." Measures of cleanliness, taken beforehand are, according to the Memorandum, of far more importance for the protection of a district against cholera than removal or disinfection of filth after the disease has actually made its appearance, and even if cholera fails to spread to this country all action taken in this direction will, by preventing disease and ill-health from other causes, in the long run turn out to be remunerative.

Immediate investigation as to the wholesomeness of water-services should be made. The sources and the reservoirs should be examined by the authorities; intermittent services should, as far as possible, give way to constant supplies; cisterns should be kept scrupulously clean, ard above all the waste-pipes leading from them should be so contrived as to flow in the open air. All accumulations of filth and house refuse should be removed regularly and at frequent intervals from the proximity of dwellings; house-drains and waste-pipes should be well ventilated, and so disconnected from the main sewers as to prevent the possibility of air from the public culverts from making its way into them. Action in these directions will do more to save households from infection than all the quarantine measures ever devised, and it is the absence of such action that has enabled cholera to spread itself broadcast throughout Egypt, notwithstanding the rigid measures of quarantine that have been adopted in that country.

\section{THE LIFE OF EDWARD HENRY PALMER}

The Life and Achievements of Edward Henry Palmer. By Walter Besant, M.A. (London: Murray, I883.)

THE tragedy of Palmer's death gives his biographer the right to look to a wider circle of readers than would in ordinary cases feel interest in the life of an Oriental scholar and explorer. Mr. Besant has used his opportunity with the skill of an accomplished story-teller. Those who have dipped into the author's imaginative works will quickly recognise the familiar methods of art by which the reader's interest is sustained and carried on, the whole narrative disposed so as to lead up to the final catastrophe, and the figure of the hero invested even from childhood with something of an unearthly glamour. . This method of treatment is a little disappointing to those who do not need to have their interest in Palmer stimulated, but only wish to learn as much about him and his work as possible; but it is fair to remember on the one hand that Mr. Besant is no Orientalist, and so naturally looks at Palmer's linguistic achievements through a mysterious haze, the effect of which is very artistically imparted to the reader's mind, and on the other hand that the exceptional nature of Palmer's powers, and the exceptional course of education in which these powers found their fitting development, are really calculated to stir the sentiment of wonder which the biographer has chosen to make the keynote of his book.

Palmer's linguistic talent was not analytical but mimetic ; it was associated in his youth with histrionic tastes; and the love of mimicry, as Prof. Nicholl has well observed in his appendix on "Palmer's Work as an Oriental Scholar," had a large part in his literary compositions in Oriental tongues. It was through the mimetic faculty-not of course by mere vulgar superficial mimicry, but by a childlike gift of sympathy and imitation-that Palmer learned languages. His teachers were men, not books; and when he learned Arabic, for example, he did not merely learn grammar and vocables, but acquired the power of thinking and expressing himself like an Arab. When he spoke or wrote an Eastern tongue he seemed to be for the time a real Oriental; to hear him recite Arabic was to feel one's self carried back to a camp in the desert. The talent, or rather the type of mind, which all this implies is very rare in the West ; in the East it is more common, though hardly in the perfection in which Palmer possessed it; and this perhaps is the reason why Oriental languages ultimately became the study of his choice. His gifts put him in thorough sympathy with the tastes and aims of modern Oriental scholarship; it was the later models of Eastern literature, themselves imitative and full of dexterous variations of fixed themes rather than of original ideas, that fascinated him and called forth his powers in not unsuccessful rivalry with the best native writers of the day. The precise character of Palmer's scholarship cannot be expressed by a single Western term. He was more than a linguist and yet less than, or other than, a scholar of the Western type ; for he was singularly destitute of the critical faculty which we esteem inseparable from scholarship. He was in a word an Oriental Adîb, a man who loved language for the feats that could be done with it, and not for the ulterior scientific purposes which are the chief concern of most Western Orientalists.

Mr. Besant does not seem to have clearly grasped the peculiar type of Palmer's learning. $\mathrm{He}$ sees that he differed from most Orientalists; but he has the curious notion that the difference lay in a sort of grammatical pedantry which Palmer lacked, and to which other men give undue importance. That of course is purely imaginary. Palmer more nearly perhaps than any other Occidental who ever lived realised the Eastern ideal of literary culture. But the best Western Orientalists have been great just because they had a different and, it must be added, a more fruitful conception of the aims and uses of linguistic knowledge than the East has attained to. In criticism, in comparative philology, in the use o language to throw light on the past history of our race, Western scholars have solved problems which the 'most accomplished Oriental never even contemplates, and in 